\title{
Venomous Terrestrial Snakes of Malaysia: Their Identity and Biology
}

\author{
Indraneil Das, Norhayati Ahmed, and Lim Boo Liat
}

\section{Contents}

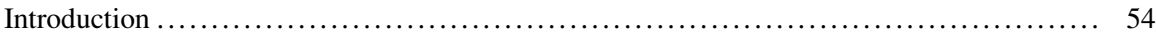

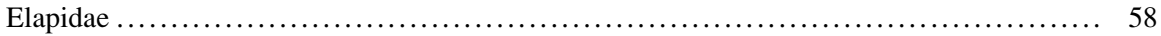

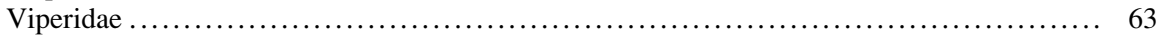

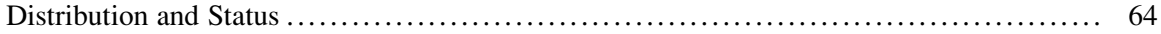

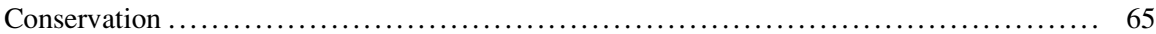

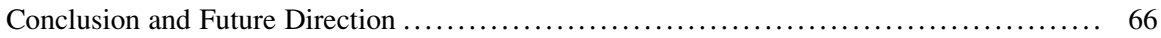

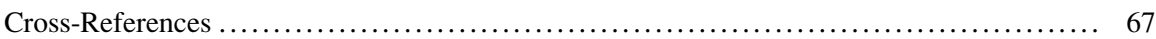

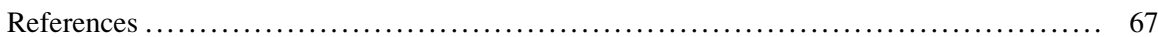

\begin{abstract}
This article presents an overview of the identity and biology of the venomous terrestrial snakes of Malaysia, from Peninsular Malaysia and the Bornean states of Sabah and Sarawak. Two families account for a majority of venomous snakes that are of medical significance - the Elapidae (cobras, kraits, and coral snakes) and Viperidae (vipers and pit vipers). Certain members of the Colubridae are capable of giving life-threatening bites to humans (especially species of Rhabdophis), but little is known of the Malaysian species of the genus.
\end{abstract}

\section{Das $(\bowtie)$}

Institute of Biodiversity and Environmental Conservation, Universiti Malaysia Sarawak, Kota Samarahan, Sarawak, Malaysia

e-mail: idas@ibec.unimas.my

\section{N. Ahmed}

School of Environment and Natural Resource Sciences, Universiti Kebangsaan Malaysia, Bangi, Selangor, Malaysia

e-mail: noryati@ukm.my; yati_68@yahoo.co.uk

\section{L.B. Liat}

Cheras, Selangor, Malaysia

e-mail: limbooliat@yahoo.co.uk 